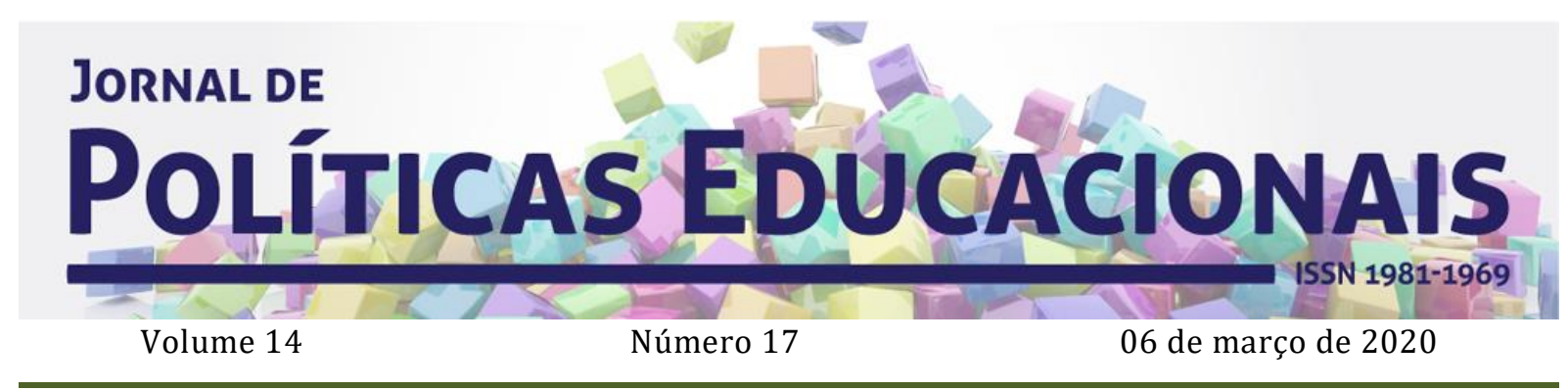

\title{
O desafio da função social docente diante das políticas educacionais em curso no Brasil
}

\section{The challenge of teachers' social role in front of current educational policies in Brazil}

\section{La función social del profesional docente en la coyuntura de las políticas educativas en curso en Brasil}

\author{
Rosimar Serena Siqueira Esquinsani ${ }^{1}$ \\ Sidinei Cruz Sobrinho ${ }^{2}$
}

Citação: ESQUISSANI, R. S. S.; SOBRINHO, S. C. O desafio da função social docente diante das políticas educacionais em curso no Brasil. Jornal de Políticas Educacionais. V. 14, n. 17. Março de 2020.

Resumo: A pesquisa questiona a função social do profissional docente na conjuntura das políticas educacionais em curso, dada a hegemonia neoliberal. Tem por metodologia a hermenêutica jurídica de políticas educacionais normativas relacionadas à formação docente, lançando mão da análise qualitativa de Programas de Governo e a revisão bibliográfica (FREIRE; DARDOT; LAVAL; GIDDENS; SENNETT; GRAMSCI). 0 objetivo é problematizar a relação do neoliberalismo com ações de políticas educacionais na atualidade, comparando as políticas normativas aos principais programas de governo em curso no Brasil e apresentar a função social do profissional docente enquanto trabalhador intelectual. As reflexões acerca dos programas de governo, ancoradas na devida revisão bibliográfica e na análise de dados, concluem pela hegemonia neoliberal na atual conjuntura nacional, mas também estabelecem cinco categorizações sobre a função social do profissional docente, enquanto possibilidade do exercício contra-hegemônico.

Palavras-chave: Neoliberalismo, Políticas Educacionais, Função social.

Abstract: This research questions the teachers' social role in the face of current educational policies in Brazil, which are influenced by economic neoliberalism. The scientific methodology used was the legal hermeneutics of the educational policy. Also, it uses a qualitative analysis of Governmental Programs and bibliographic review (FREIRE; DARDOT; LAVAL; GIDDENS; SENNETT; GRAMSCI). The objective is to

\footnotetext{
${ }^{1}$ Doutora em Educação. Professora e pesquisadora do Programa de Pós-Graduação em Educação da Universidade de Passo Fundo. Pesquisadora Pq/CNPq. Passo Fundo, RS. Brasil. Orcid: https://orcid.org/0000-0002-6918-2899. E-mail: rosimaresquinsani@upf.br 2 Professor do Instituto Federal Sul-Rio-Grandense/IFSul. Doutorando do Programa de Pós-Graduação em Educação da Universidade de Passo Fundo. Passo Fundo, RS. Brasil. Orcid: https://orcid.org/0000-0002-8826-5745. E-mail: sidineisobrinho@hotmail.com
} 
problematize how economic neoliberalismo determines educational policies and doing so, to show the teacher's social function as an intellectual worker. One conclusion is that neoliberal theories are the main infuence on the present educational policies in Brazil, following the trend worldwide. The article also concludes presenting which the teachers could perform to practice their social role against the economic neoliberalism.

Keywords: Neoliberalism, Educational Policies, Social Role.

Resumen: la investigación cuestiona la función social del profesional docente en la coyuntura de las políticas educativas en curso, dada la hegemonía neoliberal. Tiene como metodología la hermenéutica jurídica de políticas educativas normativas relacionadas con la formación docente, haciendo uso del análisis cualitativo de Programas de Gobierno y de una revisión bibliográfica (FREIRE; DARDOT; LAVAL; GIDDENS; SENNETT; GRAMSCI). El objetivo es problematizar la relación del neoliberalismo con las acciones de políticas educativas en la actualidad, comparando las políticas normativas con los principales programas de gobierno en curso en Brasil, además de presentar la función social del profesional docente como trabajador intelectual. Las reflexiones acerca de los programas de gobierno, ancladas en la derivada revisión bibliográfica y en el análisis de datos, nos conducen a considerar la hegemonía neoliberal en la actual coyuntura nacional, pero también el establecimiento de cinco categorizaciones respecto a la función social del profesional docente, en cuanto es una posibilidad del ejercicio contra lo hegemónico.

Palabras clave: neoliberalismo, políticas educativas, función social.

\section{Introdução}

Diante da atual conjuntura nacional da educação o espanto é inevitável. O contexto se estabelece, aparentemente caótico, mas organizado nas suas disfunções; nas quais se encontra a lógica neoliberal. Na relação com a escola, o neoliberalismo dissimula, ilude, aliena e usa do profissional docente como servo dos interesses do mercado e das novas estratégias do capitalismo desorganizado. Se observado com cuidado, é possível perceber os cursos escondidos nos discursos do Governo, de muitos profissionais da educação pública ou privada, e das Políticas Públicas Educacionais que se estabelecem. Este é o principal desafio do profissional docente enquanto trabalhador intelectual. Entre tantas interferências do Estado e, no uso dele, do neoliberalismo nas Políticas Públicas Educacionais, é possível identificar a trama que se enlaça e as armadilhas que espreitam o profissional docente e a educação no Brasil.

A conjuntura em debate é visível, por exemplo, tanto na Reforma do Ensino Médio, BNCC, Diretrizes para Formação dos Professores e tantas outras normativas, quanto em Programas do Governo para efetivar as políticas educacionais, tais como: Escolas Cívico Militares; Novos Caminhos e Future-se. Neste cenário o profissional docente deve questionar para onde realmente levam estes novos caminhos, qual é a função social reservada ao docente na formação inicial ou continuada, e como pode/deve agir. Cabe questionar se o projeto em curso tem espaço para a formação ou a deformação do profissional docente, enquanto trabalhador intelectual. 
O texto segue empenhado em comprovar a seguinte premissa: diante das evidências colhidas através da hermenêutica jurídica sobre as normativas das políticas educacionais, da análise de alguns Programas de Governo contemporâneos, ainda segundo a revisão bibliográfica crítica sobre as estratégias do neoliberalismo e sobre a formação docente, compreendemos que na atual conjuntura nacional das políticas educacionais, resta ao profissional docente a formação ou a deformação, lutar ou fraturar-se. Tal premissa ancora-se na inferência de Laval, para o qual o Brasil está "na vanguarda da escola neoliberal" (LAVAL, 2018, p. 12 ss).

Nesse sentido, a pesquisa questiona qual é a função social do profissional docente na conjuntura das políticas educacionais em curso, dada a hegemonia neoliberal. Tem por metodologia a hermenêutica jurídica de políticas educacionais normativas relacionadas à formação docente; análise qualitativa de alguns Programas de Governo; a revisão bibliográfica (FREIRE; DARDOT; LAVAL; GIDDENS; SENNETT; GRAMSCI), bem como a análise de dados. 0 objetivo é, por meio do estudo bibliográfico sobre a relação do neoliberalismo com as políticas educacionais e comparados às políticas normativas e aos principais programas de governo em curso no Brasil, apresentar a função social do profissional docente enquanto trabalhador intelectual. Conclui-se pela hegemonia neoliberal dominante na conjuntura nacional e por cinco categorizações da função social do profissional docente enquanto possibilidade do exercício contra-hegemônico.

\section{A função social do profissional docente na conjuntura das políticas educacionais no Brasil}

O neoliberalismo, dada a nova forma de organização do capitalismo, (financeirização; empreendedorismo, ...) corrói o caráter (SENNETT, 2009), rompe com a ideia de coletividade, embora mantenha a relação de interdependências subjetivas (GIDDENS, 2002) e, nisso, garante o processo de alienação. Assim, a pessoa alienada: "ali é nada"; mas acredita que é única e exclusivamente responsável pelo seu próprio sucesso ou fracasso. E, por acreditar nisso, ignora o "outro" ao mesmo tempo que, conforme o contexto em que sua crença de ser se fideliza, ela se submete ou oprime o "outro" e a "si mesma”. Estes, entre os quais também se incluem docentes, assim permanecem, alimentando a lógica neoliberal de oprimidos, até que "se descubram 'hospedeiros' do opressor" (FREIRE, 1987, p. 32). 
É oportuno perguntar: como que o contexto caótico das políticas educacionais e da atuação dos docentes se instaurou? Qual é a função social do profissional docente neste cenário? Tais questionamentos não colocam o docente como único ou maior responsável pela crise na educação, ao contrário, tendem justamente resgatar ao docente o seu papel principal como trabalhador intelectual e não como mero técnico operacional do ensino (LAVAL, 2018). Pretende-se a filosofia da práxis, enquanto prática docente compreendida como "a própria história em sua infinita variedade e multiplicidade, [...] como método de erudição na verificação dos fatos particulares [...] filosofia entendida como metodologia geral da história[...]" (GRAMSCI, 1999. p. 146). 0 filosofar, aqui, evidencia a obrigação epistêmica fundamentada e o exercício da autonomia docente. 0 primeiro compromisso do docente deve ser consigo mesmo. Compreender como se dá a "minha" prática docente e se a concepção que a norteia possibilita, no que lhe concerne, interpretar de que forma, enquanto docente, legitimo ou não as políticas educacionais e a conjuntura estabelecida. Se, ao menos a maioria dos que discordam da conjuntura hegemônica neoliberal atuassem com maior consciência de classe, os processos de legitimidade e legitimação seriam mais bem utilizados na estratégia para o fortalecimento contra-hegemônico. Daí resulta outra função social do profissional docente: o exercício da cidadania, da ética e da coerência. É preciso se posicionar. De toda forma, aquele não se posiciona, age por omissão e, em decorrência lógica, já se posicionou a favor do poder dominante.

0 exercício da cidadania, da ética e da coerência docente conduz à realização de outra função social, qual seja a do docente enquanto cientista social. Nessa função o docente deve ser capaz de interpretar antes de executar as políticas educacionais, no intuito de realizar a crítica e a autocrítica, uma vez que o docente é sempre parte dos processos de legitimidade e legitimação das políticas educacionais. Empiricamente podese traduzir essa lógica na hermenêutica jurídica das políticas educacionais normativas e na interpretação dos programas de governo trazidos a seguir. Optou-se pelas políticas educacionais que seguem porque é notória a preocupação alienada de muitos docentes da educação básica para a implementação da Reforma do Ensino Médio e da BNCC sem interpretar e perceber como que estas e outras políticas direcionam, capciosamente, a formação, a atuação e a própria concepção da função do profissional docente.

Iniciemos, pois, pela chamada Reforma do Ensino Médio. Esta se desenrolou mais especificamente entre os anos 2013 e 2017, principalmente por meio dos seguintes instrumentos normativos ao nível macro: PL 6.840/2013; MP 746/2016; 
Lei 13.415/2017 e RESOLUÇÃO CNE n. ํ 3/ 2018 - DCNEM. O principal argumento para a reforma, como já afirmado inicialmente, foi a da péssima qualidade da educação básica, e o desinteresse dos jovens pelo ensino. Motivos esses suficientes para se justificar e se amarrar a reforma do ensino médio à BNCC. Em suma foram mais de trinta anos entre o berço da ideia da BNCC, na CF de 1988 e a lápide normativa da BNCC em 2018. Nesse intervalo, a discussão da BNCC se passou pela LDB (1988 - 1996); PCNs (19972000); DCNs (2010 - 2011); Pactos: PNAIC, PNFEM, PNE; (2011 - 2014) até a elaboração do texto (2015 - 2018). Ao mesmo tempo, outros "nós" eram (éramos) imperceptivelmente amarrados a estes, resultando, por exemplo, na EC 95/2016 (Regime Fiscal); a Lei 13.467/2017 (altera a CLT); PEC 06/2019 (Reforma da Previdência), que impactam direta e negativamente no investimento, estrutura, vagas e carreiras docentes; e no desenvolvimento da educação pública no Brasil. Portanto, impactam, igualmente, na qualidade da educação e na possibilidade de implantação das políticas educacionais pretendidas pela BNCC e Reforma do Ensino Médio. Importante destacar que essas políticas trazem em seu corpus teórico, o discurso e terminologia conceitual humanista e do desenvolvimento do bem-estar social pretendido pelo movimento contra-hegemônico, mas que usa isso como estratagema para ocultar as verdadeiras intencionalidades de colonização neoliberal da escola (DARDOT; LAVAL, 2016; LAVAL; 2018).

Como que tais políticas citadas se relacionam, influenciam ou são influenciadas por políticas educacionais específicas sobre a formação docente inicial e/ou continuada? Vejamos: a Lei 13.005/2014, traz a Meta 15, segundo a qual até o prazo de um ano após o PNE (portanto: 2015/2016) seria “assegurado que todos os professores da educação básica possuam formação específica de nível superior, obtida em curso de licenciatura na área de conhecimento em que atuam." (BRASIL, 2014, s. p). Na mesma lei, uma das formas de se garantir isso, seria por meio da Estratégia 15.13, que, no que lhe concerne, iria "desenvolver modelos de formação docente para a educação profissional [...] na Rede Federal [...] de educação profissional, [...]." (BRASIL, 2014, s. p).

Ocorre que, vencido o prazo inicial e já prorrogado uma vez, em razão da Reforma do Ensino Médio e da BNCC, a Lei no 13.415/2017, Art. 11, volta a prorrogar o prazo por mais "2 (dois) anos, contados a partir da data de publicação da BNCC, para que a referida adequação curricular da formação docente seja implementada." (BRASIL, 2017, s. p.). Ora, fica explícito que a formação docente será orientada pela organização da BNCC, quando a Lei 13.415/2017 que trata da Reforma do Ensino Médio, também altera o Art. 62 da LDB, 
ao dispor no parágrafo 8ำ que "os currículos dos cursos de formação de docentes terão por referência a Base Nacional Comum Curricular" (BRASIL, 1996, s. p.). Ocorre que, ao redigir esse trabalho já é quase findo o ano 2019, portanto o fim da previsão do último prazo para alteração das Diretrizes Curriculares Nacionais para a formação inicial ao nível superior (cursos de licenciatura, cursos de formação pedagógica para graduados e cursos de segunda licenciatura) e para a formação continuada docente (que também foi prevista pela Resolução CNE/CP no 2, de 1o julho de 2015) houve nova alteração do prazo pelo PARECER CNE/CP n.o: 7/2019, enquanto isso, muitos estabelecimentos de ensino e docentes preocupam-se somente em como implementar a BNCC porque há prazos para se cumprir, principalmente no que se refere à organização do currículo por itinerários formativos e por habilidades e competências. Isso, sem se questionar se há alternativas contrárias viáveis.

Nesse lapso temporal de cinco anos, a cada ano uma geração de docentes foi graduada na formação inicial. Docentes estes que irão para as escolas ensinar com base numa organização curricular dada pela BNCC, para a qual não foram qualificados, e da qual tiveram tolhido o direito de participar intelectualmente. Se não há nisso uma estratégia mal dissimulada da lógica mercantil de alienação do trabalho docente e de desmoralização deste profissional na conjuntura nacional, somadas às declarações públicas de agentes públicos (gestores da educação), então, como anunciava o alerta lido por Dante à porta do Inferno, toda esperança deve ficar de fora.

Ou seja, o docente não será protagonista direto enquanto profissional intelectual da política educacional que organiza o currículo na educação básica, nem da organização curricular da própria formação docente. Resta a ele o papel de técnico operacional do currículo desenhado por políticas educacionais normativas nas quais seu espaço efetivo e ativo de participação e produção é seriamente minorado pela estratégia dominante do neoliberalismo que provoca a hibridação entre escola e empresa, estado e capital. (DARDOT; LAVAL, 2016; LAVAL, 2018; SENNETT, 2009).

Continuando a análise pretendida, constata-se, na própria lei da Reforma do Ensino Médio, o que corresponde ao atual Art. 36, § 3ํ da LDB, o dispositivo jurídico segundo o qual "[...] poderá ser composto itinerário formativo integrado, que se traduz na composição de componentes curriculares [...] BNCC e dos itinerários formativos, considerando os incisos I a V do caput." (BRASIL, 1996, s. p.). A hermenêutica desta norma levanta questões de extrema relevância, tais como: por quais motivos muitos 
estabelecimentos de ensino e muitos docentes estão tão afoitos e preocupados com qual itinerário formativo ofertar e como (re) organizar os planos de ensino para atender às Habilidades e Competências da BNCC? A proposta de oferta da educação básica por itinerários formativos é, efetivamente uma possibilidade de diversificação curricular para elevar o interesse dos estudantes pela educação básica, ou uma estratégia para solucionar a falta de docentes nas escolas públicas e de docentes com formação específica nas áreas de atuação? A organização por itinerários formativos conforme as áreas gerais (LDB, Art. 35 - A), oculta a intenção da formação de docentes por polivalentes por áreas amplas e não mais por áreas específicas? Se não, por que tanta ênfase nesta e nas demais legislações de que a Diretrizes Nacionais para formação de docentes será com base na BNCC, que por sua vez serve para alimentar a organização curricular prevista na Reforma do Ensino Médio? O quinto itinerário formativo, direcionado à formação técnica, quando desintegrado dos demais itinerários e menorizado pela formação comum pretendida na BNCC que será de no máximo até $1.800 \mathrm{~h}$, pretende a profissionalização para o mundo do trabalho ou a retomada do ensino profissionalizante tecnicista para o mercado de trabalho? Trata-se de uma concepção de ensino que separa o trabalho intelectual do trabalho braçal, considerando agora, no neoliberalismo, trabalho braçal como sendo sinônimo do domínio de habilidade e competências intelectuais que se adaptam ao novo espírito do capitalismo desorganizado e a exigência de um perfil profissional empreendedor e inovador, mas extremamente fluidos, voláteis e flexíveis? (SENNETT, 2006).

Afinal, se o estabelecimento de ensino e os docentes defendem, efetivamente, a formação integral dos educandos, por que não seguir o disposto no Art. 36 , § $3^{\circ}$ da LDB e organizar o currículo de modo integrado atendendo aos quatro primeiros (no caso das escolas que não atuam como formação profissional) ou aos cinco itinerários formativos, a exemplo do que estão fazendo os Institutos Federais ao nível nacional para resistir à fragmentação curricular e à extinção das áreas das humanidades do currículo como possibilita a Lei 13.415/2017 e a BNCC? Se, até então, a organização curricular buscava o pleno desenvolvimento da pessoa humana, o preparo para o exercício da cidadania e a preparação para o trabalho, conforme prevê o Art. 205 da CF/88, portanto, a formação integral; como é que fragmentando ou possibilitando aos indivíduos, acesso apenas a uma parte do conhecimento científico, cultural, econômico e tecnológico historicamente 
produzido pelo trabalho humano, fazendo com que se percam e se distanciem uns dos outros entre itinerários lineares e fechados, possibilitará tal formação integral?

Ou seja, deve-se admitir que: 1) a Reforma do Ensino Médio redunda em inconstitucionalidade porque possibilita ofender a Carta Magna; 2) Não se buscava a formação integral ou não deve ser mais prioritária; 3) Embora se defenda discursivamente a formação integral, concretamente se realizará uma educação fragmentada, tecnicista, elitista e direcionada apenas para as necessidades do mercado capitalista; ou 4) os docentes aceitaram sua condição de operador técnico da educação neoliberal a serviço do aluno cliente, em estabelecimentos de ensino que mais se assemelham a uma empresa (LAVAL, 2018) produtora de ensino, pesquisa e/ou extensão por demanda do mercado que a uma escola responsável por promover o bemestar social por meio da educação reflexiva, crítica e responsável.

No que tange mais diretamente à formação docente relacionada explícita ou implicitamente nestas políticas educacionais, tem-se que o Art. 35-A da LDB (BRASIL, 1996. s. p.) ao organizar a BNCC por áreas do conhecimento e ao prever no Art. $62 \S 8^{\circ}$, que a formação dos docentes se dará conforme a BNCC, induz a formação de docentes por áreas do conhecimento. Assim, poder-se-á abrir ainda mais espaço para que a formação inicial do docente exclua a habilitação específica e, em consequência, também se leve essa compreensão para novas políticas educacionais que, de modo rasteiro, façam uma formação complementar breve aos docentes já licenciados, para que também atuem por áreas do conhecimento. Em decorrência disso, a escola não precisa mais de um docente de química, um docente de física e um de biologia, por exemplo, para atuar na área de conhecimento e itinerário formativo voltado para ciências da natureza e suas tecnologias. Bastará ter um docente licenciado em ciências da natureza para que atenda a demanda que até então exige três professores no ensino médio.

Coincidência não é, dado que, conforme o Censo da educação Básica 2018 (INEP, 2019), uma, a cada três disciplinas, é ministrada por docente sem formação específica. No ensino médio 61, 9\% das disciplinas são dadas por professores licenciados na área específica. Também não é por acaso que em outubro de 2019 o MEC lançou o Programa Novos Caminhos, direcionada para a Rede Federal de Educação Profissional e, no qual, uma das metas é a criação de 21.000 (vinte e uma mil) novas vagas de licenciaturas em ciências da natureza e matemática, até 2022. Ocorre que, conforme dados da Rede Federal, os IFs, em 2018, ofertaram 5.229 vagas nessas áreas para licenciatura, portanto, 
implicaria elevar em 401,6\% a capacidade de oferta dos IFs nessas áreas. Como, se já faltam docentes e a EC 95/2016 impede a contratação de novos servidores públicos? Só resta algumas alternativas: parceria com a iniciativa privada; o reconhecimento do docente com notório saber; e cursos rápidos de formação pedagógica por áreas.

O sucateamento da formação e da condição docente continua. Se tomado o Art. 61 da LDB, a Lei 13.415/2017 incluiu o inciso IV. Nesse se abriu espaço para que profissionais atuem na educação básica como docentes sem a licenciatura, e sem formação ao nível superior, pois admite "profissionais com notório saber reconhecido pelos respectivos sistemas de ensino, para ministrar conteúdos de áreas afins à sua formação ou experiência profissional” (BRASIL, 1996. s. p.). Embora a previsão normativa afirme que será "exclusivamente para atender ao inciso V do caput do art. 36" (idem), ou seja, do itinerário formativo para a educação profissional, com isso apenas deixa claro que a formação docente ao nível superior de cursos de licenciatura é dispensável, afinal, se vale para o itinerário formativo técnico, porque não pode passar valer também para os demais? Além disso, ao exigir que tal notório saber seja atestado "por titulação específica ou prática de ensino em unidades educacionais da rede pública, ou privada, ou das corporações privadas em que tenham atuado" (idem), a política faz nenhuma menção ou cuidado para definir algum limite e/ou condição de certificação, deixando completamente em aberto a importância da formação docente para a educação básica.

Em complemento à previsão do notório saber, inovando na legislação a RESOLUÇÃO CNE n. ${ }^{\circ}$ 3/ 2018, que trata das DCNEM, atualizadas para se adequar à Lei 13.415/2017 previu no Art. 29, parágrafo único que, além do notório saber, a docência na “[...] formação técnica e profissional poderá ser realizada por profissionais com comprovada competência técnica referente ao saber operativo de atividades inerentes à respectiva formação técnica e profissional". As DCNEM apenas citam a necessidade de comprovação de competência técnica. Ou seja, nem sequer é necessária formação acadêmica ao nível superior ou básico para se comprovar competência técnica. Ao menos, até o momento, nada foi esclarecido sobre essa possibilidade.

Muitos alegam que se trata apenas de uma exceção e a lei não prevê que se possa estender essa possibilidade aos demais itinerários formativos e/ou níveis e etapas da educação formal. Se a previsão legal da exceção é suficiente para garantir a efetividade da proposta da política educacional, por quais razões as demais políticas previstas 
normativamente não foram cumpridas? Se a interpretação aqui desprendida da lei foi possível, felizmente até que se saiba, como mero exercício reflexivo, o que a impede de ser praticada? Já se comprovou amplamente que apenas a normativa formal não é suficiente e que o neoliberalismo sabe perfeitamente legitimar formalmente como interesse público o que é de interesse privado. Também já se demonstrou que confiar no "bom senso" dos profissionais envolvidos na concretização das políticas educacionais não é suficiente, do contrário, o neoliberalismo não estaria posto enquanto hegemonia predominante.

Em síntese, a conjuntura das políticas educacionais, no que tange à formação docente, dentre outros prejuízos, faz com que a "imagem do graduado no curso universitário que se dedica ao ensino se move entre a de alguém que renunciou a ambição econômica, em favor de uma vocação social e a de quem não soube nem conseguiu encontrar algo melhor." (ENGUITA, 1991. p.45).

Como que as possibilidades de concretização das conclusões inferidas da hermenêutica realizada já estão em curso no contexto educacional brasileiro? Alguns exemplos concretos evidenciam isso. Em 2018, nos dias 25 a 26 de setembro, o MEC/SETEC /SEB convocaram uma reunião com representantes da Rede Federal de educação profissional (IFs, CEFETs...), Rede Estadual, Sistema S e iniciativa privada, para tratar dos "Desafios e perspectivas no itinerário de formação técnica e profissional no Ensino Médio." Na ocasião apresentaram propostas nas quais estava explícita a fragmentação curricular, o ensino médio integrado como sendo "modelo antigo", a contratação de docentes por notório saber; a inspiração na organização já adotada por instituição da iniciativa privada como modelo a guiar a educação pública; o estabelecimento de parcerias público e privadas, dentre outras ideias que apenas reforçam a colonização do Estado pela lógica neoliberal do novo capitalismo. Mais recentemente, no ano 2019, outros programas de governo seguem no mesmo sentido, tais como as Escolas Cívicos Militares, o Programa Future-se e o Programa Novos Caminhos (já mencionado); além de um ataque generalizado à educação pública como contingenciamento de recursos, o corte de bolsas de pesquisa, as propostas de reformulação e enxugamento da CNPQ e da CAPES; redução da PROUNI, FIES; desvalorização das humanidades e uma miscelânea inacreditável de equívocos e declarações infundadas do governo e ministério da educação, conduzindo a população 
contra a educação pública e aos profissionais da educação e a favor da privatização e mercantilização das escolas.

\section{Conclusão}

Esse é, em resumo o cenário da conjuntura das principais políticas educacionais em pauta que, infelizmente revelam o contexto hegemônico no qual predomina o neoliberalismo. Contudo, pergunta-se: se o contexto atual é hegemônico, existe a possibilidade do exercício contra-hegemônico por meio da atuação do docente dentro das instituições de ensino - em atividades de ensino, pesquisa e extensão - e fora delas? Eis a questão que abre espaço ao contrapor e ao agir do profissional docente. Tal questão deve ser aprofundada e provocada por e com os profissionais docentes na lógica da filosofia da práxis que possibilita o exercício contra-hegemônico.

Para isso, é imprescindível concordar que, dentre outras formas de dizer, a função social do profissional docente deve permear e ser permeada por: 1) Fundamentação epistêmica e autonomia docente; 2) Participação docente nos processos de legitimidade e legitimação das políticas educacionais; 3) Exercício da Cidadania, Ética e Coerência docente; 4) O docente enquanto cientista social: crítica e autocrítica; 5) Consciênciadesi e de "classe" para a atividade contra-hegemônica. Em síntese, é imperativo resgatar a função social do profissional docente enquanto trabalhador intelectual que ao reivindicar para si essa função, também promove a dignidade humana solapada pelo neoliberalismo.

\section{Referências}

BRASIL. Lei no 11.892, de 29 de dezembro de 2008. Institui a Rede Federal de Educação Profissional, Científica e Tecnológica, cria os Institutos Federais de Educação, Ciência e Tecnologia, e dá outras providências. D.O.U. Seção 1, de 30 de dezembro de 2008. Brasília, DF, 2008.

BRASIL. Lei no 9.394 de 20 de dezembro de 1996. Estabelece as Diretrizes e Bases da educação nacional. Disponível em < https://www.planalto.gov.br/ccivil_03/Leis/L9394.htm> Acesso em: 10 de abril de 2018.

BRASIL. Constituição Federal de 1988. Promulgada em 5 de outubro de 1988.

Disponível em <http://www.planalto.gov.br/ccivil_03/constituicao/constituição.htm>.

BRASIL. Medida Provisória 746, de 22 de setembro de 2016. Disponível em <http://www.planalto.gov.br/ccivil 03/ Ato2015-2018/2016/Exm/Exm-MP-74616.pdf > . Acesso em: 17 de agosto de 2019. 
DARDOT, P.; LAVAL, C. A nova razão do mundo: ensaio sobre a sociedade neoliberal. São Paulo: Boitempo, 2016.

ENGUITA, Mariano F. A ambigüidade da docência: entre o profissionalismo e a proletarização. Revista Teoria \& Educação, n. 4, p. 41-61, 1991.

FAORO, Raymundo. Os Donos do Poder: formação do patronato político brasileiro. RJ. 0 globo. $3^{\underline{a}}$ ed, 2001.

FREIRE, Paulo. Pedagogia do oprimido. 17aㅡ ed. Rio de Janeiro: Paz e Terra, 1987.

GOMES, Candido Alberto. Darcy Ribeiro. Recife: Fundação Joaquim Nabuco, Editora Massangana, 2010.

GIDDENS, Anthony. Modernidade e Identidade. Rio de Janeiro: Jorge Zahar, 2002.

GRAMSCI, Antonio. Cadernos do Cárcere, Volume 1: introdução ao estudo da filosofia, a filosofia de Benedetto Croce. Edição e Tradução de Carlos Nelson Coutinho. Rio de Janeiro: Civilização Brasileira, 1999.

INEP. Censo da Educação Básica 2018. Disponível em: < http://www.publicacoes.inep.gov.br/resultados-e-resumos > Acesso em 21 de outubro de 2019.

LAVAL, Christian. A escola não é uma empresa: o neo-liberalismo em ataque ao ensino público. Londrina: Editora Planta, 2004.

NUSSBAUM, Martha. Sem fins lucrativos: porque a democracia precisa das humanidades. São Paulo: WMF Martins Fontes, 2015.

SENNETT, Richard. A corrosão do caráter: as consequências pessoais do trabalho no novo capitalismo. 14를 ed. - Rio de Janeiro: Record, 2009.

SENNETT, Richard. A cultura do novo capitalismo. Rio de Janeiro: Record, 2006. 


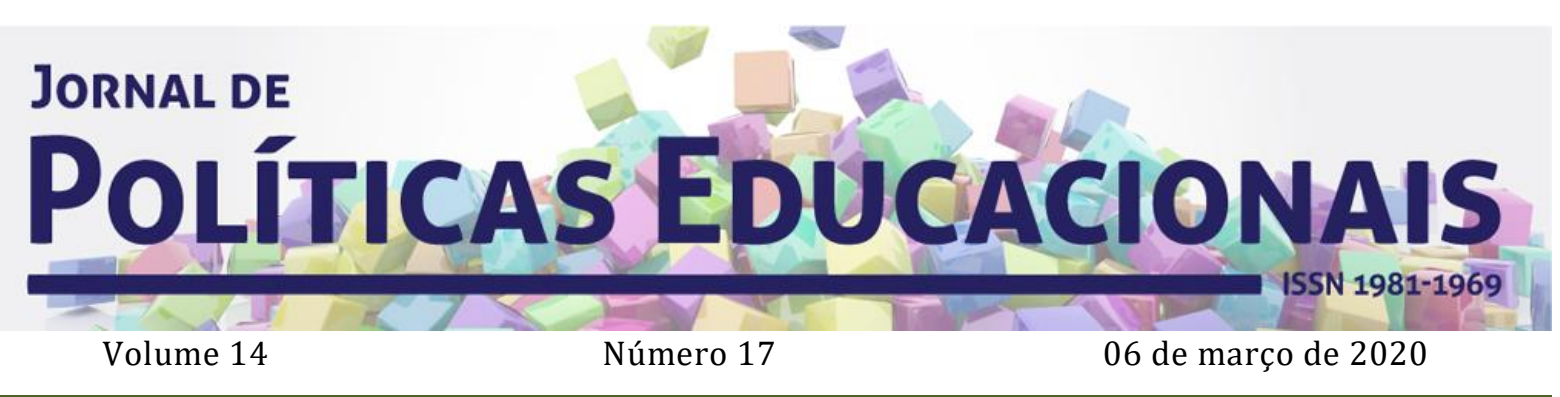

(C)

SORERTIGHIS RESERNED O Copyright é retido pelo/a autor/a (ou primeiro co-autor) que outorga o direito da primeira publicação ao Jornal de Políticas Educacionais. Mais informação da licença de CreativeCommons encontram-se em http://creativecommons.org/licenses/by-nc-nd/2.5. Qualquer outro uso deve ser aprovado em conjunto pelo/s autor/es e pelo periódico.

JoRnal DE PolíticAs EduCACIONAIS é uma publicação do Núcleo de PolíticasEducacionaisdo Setor de Educação da Universidade Federal do Paraná - NuPE/UFPR, em consórcio com a Linha de Pesquisa em Políticas Educacionais do Programa de Pós-Graduação em Educação - PPGE/UFPR, que aceita colaboração, reservando-se o direito de publicar ou não o material espontaneamente enviado à redação. As colaborações devem ser enviadas ao NuPE/UFPR, conforme orientações contidas nas páginas do periódico na internet: http://revistas.ufpr.br/ipe.

Indexação:

BBE - Biblioteca Brasileira de Educação (MEC/INEP)

Clase (Base de Datos Bibliográfica de Revistas de Ciencias Sociales y Humanidades)

Diadorim - Diretório de Política de Acesso Aberto das Revistas Científicas Brasileiras (IBICT)

Google Scholar

Index Copernicus

Portal de Periódicos (CAPES)

SER - Sistema Eletrônico de Revistas da Universidade Federal do Paraná (SER/UFPR)

Sumários de Revistas Brasileiras (FUNPEC-RP)

DRJI - Directory of Research Journals Indexing

(Periódico integralmente disponível apenas em via eletrônica)

Jornal de Políticas Educacionais / Núcleo de Políticas Educacionais da Universidade Federal do Paraná NuPE/UFPR - v.1, n. 1 (1ํo semestre de 2007) - Curitiba: NuPE/UFPR.

Volume 14, número 17 - Março de 2020

ISSN 1981-1969

1. Educação - Periódicos. 2. Política Educacional - Periódicos. I. NuPE/UFPR

Comitê Editorial:

Elisângela Scaff (UFPR)

Daniela de Oliveira Pires (UFPR)

Conselho Editorial:

Andréa Barbosa Gouveia (UFPR - Brasil), Cesar Tello (Universidad Nacional Tres Febrero, Argentina), Fernanda Saforcada (Universidad de Buenos Aires - UBA - Argentina), Gladys Beatriz Barreyro (USP Brasil), Gustavo Enrique Fischman, (Arizona State University - USA), Jefferson Mainardes (UEPG - Brasil), João Ferreira de Oliveira (UFG - Brasil), Juca Gil (UFRGS - Brasil), Luiz Souza Júnior (UFPB - Brasil), Ney 
ESQUISSANI, R. S. S.; SOBRINHO, S. C. O desafio da função social docente diante das políticas educacionais em curso no Brasil

Cristina Monteiro de Oliveira (UFPA - Brasil), Nicolás Bentancur, (Universidad de la República de Uruguay), Robert Verhine (UFBA - Brasil), Rosana Cruz (UFPI - Brasil), Rubens Barbosa Camargo (USP - Brasil), Sebastián Donoso Díaz (Universidad de Talca - Chile), TheresaAdrião (UNICAMP - Brasil), Vera Peroni (UFRGS - Brasil).

Créditos e Agradecimentos:

Revisão de Língua Portuguesa, Abstract e Resumen: PROGRAMA DE APOIO ÀS PUBLICAÇÕES CIENTÍFICAS PERIÓDICAS DA UFPR

Arte e diagramação: TIAGO TAVARES (tiagotav@gmail.com)

Jornal de Políticas Educacionais

Universidade Federal do Paraná

Setor de Educação

Núcleo de Políticas Educacionais - NuPE/UFPR

Avenida Sete de Setembro, 2645

$2^{\circ}$ andar, Sala 213

80.230-010 - Curitiba - PR - Brasil

Tel.: 41-3535-6264

jpe@ufpr.br

http://revistas.ufpr.br/jpe 